\title{
Assessment of Patients Misunderstanding of Dosing Instructions Among Outpatients in Dessie Referral Hospital, Northeast Ethiopia
}

This article was published in the following Dove Press journal: Risk Management and Healthcare Policy

\section{Yohannes Mengesha (iD) Eskedar Amare}

Department of Pharmacy, College of Medicine and Health Sciences, Wollo University, Dessie, Ethiopia
Correspondence: Yohannes Mengesha Email joymengesha@gmail.com
Background: Lack of clear and precise oral and written information from both the doctors and/or pharmacists on the management of prescribed medication has led to therapeutic failure, as a result of patients not comprehending instructions. Incorrect interpretation of labels can lead to incorrect usage of medication therefore the occurrence of medication error and/or adverse event. The concern of this study was to assess misunderstanding of dosing instructions among outpatients in Dessie Referral Hospital (DRH).

Methods: An institution-based cross-sectional study was conducted on 384 outpatients at DRH from February 10 to March 15, 2019. Study subjects were selected by using a systematic random sampling technique and data was collected by using questionnaires and observation. The data was coded individually and entered in a computer using Epi Info ${ }^{\mathrm{TM}}$ version 3.5.1 and then exported to SPSS version 23.0 for analysis. Univariate analyses were used to describe the categorical variables. Chi-square test was used to assess association of variables with primary outcome. P-value $<0.05$ was considered as statistical significance.

Results: This study showed that most of the respondents $n=298$ (77.6\%) misunderstood more than one dosage instruction, $8.75 \%$ misunderstood the dose, $51.3 \%$ misunderstood the frequency while $58.59 \%$ misunderstood the duration of treatment. The misunderstanding was higher for labeled medications (11.4\%) than unlabelled (7.7\%).

Conclusion: The prevalence of misunderstanding of dosing instruction was high in outpatients of DRH. Hence standard procedures must be developed to provide easy and clear dosing instructions to patients, and continuous training must be provided for pharmacists on proper communication of dosing instructions to patients.

Keywords: dosing instruction, DRH, outpatients

\section{Background}

An optimal medication treatment outcome is largely dependent upon patient compliance. ${ }^{1}$ Poor patient compliance and subsequent unintentional misuse of a prescription drug is a root cause of medication error, poor adherence and worse health outcomes. ${ }^{2}$ Both the duration of therapy and the dosage regimen, thus the timing of drug administration, is considered an important aspect of drug therapy. ${ }^{3}$ Drug administration is not a common issue in an inpatient setting, whereby administration is done by a medical professionals. However, for an outpatient setting patient's best source of information regarding medication they are prescribed are those on the labels. ${ }^{4}$

It becomes the responsibility of the pharmacist to promote the quality use of medicines by ensuring that a patient receives the required information. This can be 
achieved by counseling which should be reinforced with both verbal and written instruction including labels attached to the immediate container of dispensed medicines. ${ }^{5}$ Each label placed on a prescription container becomes important as they are the sole, tangible source of dosage and usage information for patients regarding their medication. Therefore different pharmacies have different methods of writing instructions for patients which are placed on the medication container. As a result, interpretation of labels placed on medication containers mainly depends on counseling provided and patients' ability to understand the labels. ${ }^{6,7}$ Incorrect interpretation of labels can lead to incorrect usage of medication, thereby causing occurrence of medication error and/or adverse event. ${ }^{4}$ Various research regarding how patients interpret prescription labels and auxiliary labels on medication containers has been done the US. One-third of the adverse events from the 1.5 million events happened in the outpatient setting. $^{7,8}$

Provision of appropriate health education is one of the responsibilities of pharmacists who offer ongoing education on medicine management, monitoring and advice to the population. ${ }^{9}$ About $50 \%$ of the medications are prescribed and dispensed in the wrong way. From these $50 \%$ of meidcations are not taken correctly. ${ }^{10}$ Pharmacists play a role in educating the patients about drug related information (duration of therapy, common side effects, therapeutic indications and contra-indications) during patient counseling on discharge medication. ${ }^{10,11}$

According to a study conducted in Northeast Ethiopia about $80.7 \%$ of clients agree that they expect counseling from the pharmacists, while $51.2 \%$ of the pharmacists provided the counseling without being asked for advice. ${ }^{12}$ Failure to provide appropriate information in an easy and understandable way leads to insufficient medication adherence, and this can be corrected by patient counseling and education. But in Ethiopia, the provision of counseling services which is about $60 \%$ is below the standard services. ${ }^{13}$.

One of the major services that are expected from pharmacists practicing dispensing in Ethiopia is provision of clear and adequate information about medications which gets little attention in Ethiopia. There are various forms of medication errors that occur, however, one of the majority contributing causes of medication error which occur in an outpatient setting is an improper understanding of the instructions on prescription container labels which usually results in incorrect administration of medication. ${ }^{14}$
Lack of oral and written information from both the doctors and/or pharmacists on the management of prescribed medication has led to therapeutic failure as a direct result of patients not comprehending instructions. Studies have found that $46 \%$ and $56 \%$ of patients misunderstood one or more dosage instructions ${ }^{3}$ and one or more auxiliary warnings, respectively. ${ }^{4}$ The concern of this study was to assess patient misunderstanding of dosing instructions among outpatients in Dessie Referral Hospital (DRH).

\section{Methods \\ Study Area and Period}

An institution-based descriptive cross-sectional study design was employed. The study was conducted at the DRH outpatient pharmacy from February 10 to March 15, 2019. The hospital is situated in Dessie city, $401 \mathrm{~km}$ away from Addis Ababa, the capital city of Ethiopia. The hospital provides several health services for patients in the surrounding area and the nearby districts. The hospital consists of 4 pharmacies (outpatient pharmacy, inpatient pharmacy, emergency pharmacy and ART pharmacy).

\section{Source and Study Population}

The source population was outpatients, who came to the outpatient pharmacy of DRH to fill prescribed medications, the adolescent and adult patients who came to the outpatient pharmacy of DRH for filling of prescribed medications were included.

\section{Inclusion Criteria and Exclusion Criteria}

Adult outpatients who volunteered to participate, received their medication and dosing instructions from DRH outpatient pharmacy were included in the study. While pediatric patients and outpatients whose medication was delivered by a healthcare provider (e.g., injections), mentally ill patients and patients with hearing and speaking disability, were excluded from the study.

\section{Sample Size Determination and Sampling}

The required sample size was determined by using simple population proportion formula by considering $50 \%$ proportion, $95 \%$ confidence interval and 5\% margin of error. Using this sampling size estimation method a total sample size of 384 was obtained. $5 \%$ of the size was added to account for non-response rates and a total of 404 
outpatients were taken from the study population. Study subjects were selected by using a systematic random sampling technique.

\section{Data Collection and Quality Assurance}

The main tool for data collection was a semi-structured, face-to-face interview using a standardized questionnaire. A brief questionnaire was used to record, self-report demographic details of the participants (including age, gender, education level and ethnicity) and dosing instruction understandings. Data were collected using a pre-tested interviewer-administered questionnaire. The principal investigator was involved in the data collection. Data was collected by both interview and observation, and for patients who received more than one medication the patient selected one medication for the investigation and the correctness of their responses were evaluated by clinical pharmacists. To ensure data quality, the data collection tool was pre-tested on $10 \%$ of the outpatients. The principal investigator supervised the data collection daily and corrected any inconsistencies. Regular cross-checking and inspection of the data collection tool were also done to ensure completeness of the data.

\section{Data Process and Analysis}

The collected data were coded and entered into a computer using Epi $\mathrm{Info}^{\mathrm{TM}}$ version 3.5.1 and were then exported to SPSS version 23.0 for analysis. Univariate analyses were used to describe the categorical variables (frequency and percentage distributions of different characteristics). Chisquare test was used to assess association of variables with primary outcome. P-value $<0.05$ was considered as statistical significance.

\section{Results}

\section{Socio-Demographic Characteristics}

From the 404 outpatients, 384 of them volunteered and responded to the interview, giving a response rate of $95 \%$. Therefore the response of 384 outpatients were analyzed and reported. Of the total respondents, $256(66.7 \%)$ were male, $101(26.30 \%)$ of respondents were aged from 25 to 34 years old. Concerning the educational background about 153 (39.84\%) were illiterate. About 241 (62.7\%) of the outpatients involved in this study were permanent residents of rural areas. Of the total 384 respondents, 203 $(52.86 \%)$ of them were Amhara in ethnicity followed by Oromia (Table 1).
Table I Socio-Demographic Characteristics of Outpatients at Dessie Referral Hospital from February 10 to March 15, 2019

\begin{tabular}{|l|l|l|}
\hline Variables & Category & Frequency (\%) \\
\hline Sex & Male & $256(66.7)$ \\
& Female & $128(33.3)$ \\
\hline Age (years) & $15-24$ & $30(7.8)$ \\
& $25-34$ & $101(26.3)$ \\
& $35-44$ & $77(20.05)$ \\
& $45-54$ & $98(25.52)$ \\
& $55-64$ & $69(17.97)$ \\
& +65 & $9(2.3)$ \\
\hline \multirow{2}{*}{ Educational status } & Illiterate & $153(39.84)$ \\
& Primary school & $132(34.37)$ \\
& Secondary school & $72(18.75)$ \\
& Higher education & $27(7.03)$ \\
\hline Residence & Urban & $143(37.3)$ \\
& Rural & $241(62.7)$ \\
\hline \multirow{2}{*}{ Ethnic group } & Amhara & $203(52.86)$ \\
& Oromo & $114(29.68)$ \\
& Tigray & $55(14.3)$ \\
& SNNP & $12(3.12)$ \\
\hline
\end{tabular}

\section{Patients Misunderstanding Dosage Regimen Instructions}

More than half of the respondents 230 (59.89\%) reported an error in frequency of drug administration, they misunderstood the specified hourly interval, number of doses taken per day and both time interval and number of doses taken per day. Overall, 297 (77.34\%) patients misunderstood the dosage instructions (Table 2).

Concerning the distribution of patients misunderstanding of dosing instruction by general characteristics: 8 (21.6\%), 20 (9.85\%), 20 (11.43\%), 17 (11.04\%) and 34 $(13.44 \%)$ of the patients in the age range between +65 , male, were illiterate, came from rural areas and misunderstood dose of drug administration, respectively. Respondents, i.e. 29 (76.31\%), $146 \quad(74.11 \%), 45$ $(81.81 \%), 118(76.62 \%), 154(60.88 \%)$ of the patients in the age range $45-54$ years, female, were illiterate, came from rural area, and misunderstood frequency of drug administration, respectively, and $17 \quad(47.22 \%), 86$ (43.65\%), 31 (56.36\%), 66 (42.86\%), 54 (48.66\%) of the patients in the age range 15-24, were illiterate and came from a rural area (Table 3).

According to the findings of this study, misunderstanding of dosing instruction was higher in labeled (written) medication than the unlabeled ones (verbal labels). 
Table 2 Percentage of Misunderstanding Dosing Instructions Among Outpatients in Dessie Referral Hospital, from February 10 to March 15, 2019

\begin{tabular}{|l|l|}
\hline Variables & Frequency (\%) \\
\hline Name of medication vs misunderstanding \\
\hline $\begin{array}{l}\text { Correct } \\
\text { Incorrect }\end{array}$ & $\begin{array}{l}296(77.08) \\
86(22.4)\end{array}$ \\
\hline Amount of dose administration vs misunderstanding \\
\hline $\begin{array}{l}\text { Correct } \\
\text { Incorrect }\end{array}$ & $\begin{array}{l}8(2.08) \\
376(97.91)\end{array}$ \\
\hline Frequency of drug administration vs misunderstanding \\
\hline $\begin{array}{l}\text { Correct } \\
\text { Incorrect }\end{array}$ & $\begin{array}{l}230(59.89) \\
154(40.10)\end{array}$ \\
\hline Duration of treatment vs misunderstanding \\
\hline $\begin{array}{l}\text { Correct } \\
\text { Incorrect }\end{array}$ & $\begin{array}{l}159(41.40) \\
225(58.59)\end{array}$ \\
\hline One or more dosage regimen instruction vs Misunderstanding \\
\hline $\begin{array}{l}\text { Correct } \\
\text { Incorrect }\end{array}$ \\
\hline
\end{tabular}

Thirteen (11.40\%), 83 (72.81\%), $51(44.74 \%)$ of the patients misunderstood the dose, frequency, and duration of drug administration, respectively, from the labeled medication (Table 4). Educational status was shown to have a significance influence on patient misunderstanding of the dose $\left(\mathrm{p}=0.000, \chi^{2}=132.51\right)$, misunderstanding of frequency $\left(\mathrm{p}=0.0001, \chi^{2}=68.94\right)$ and misunderstanding of the duration $\left(\mathrm{p}=0.000, \chi^{2}=91.83\right)$ (Table 3$)$.

\section{Discussion}

According our study, from the patient characteristics, educational level is significantly associated with misunderstanding of dosing instructions while sex characteristics has no relationship with misunderstanding of dose $\left(\mathrm{p}=0.087, \chi^{2}=5.56\right)$ which shows $\mathrm{p}$-value greater than 0.05 . This is similar to studies done in Nekemte ${ }^{15}$ and Wollega, ${ }^{18}$ Ethiopia which showed that patients with low literacy were less able to understand instruction compared to those with adequate literacy.

According to the findings of this study most of the respondents 298 (77.6\%) misunderstood more than one dosage instruction. The result was approximately similar to studies done in Nekemte $(77.3 \%)^{15}$ and Wollega $(77.3 \%)^{16}$ Southwest Ethiopia but higher than studies done in America $(46.3 \%)^{17}$ and Brazil $(38.2 \%) .{ }^{18}$ Better understanding, awareness of the community, and the health literacy status of the community towards drug information may be attribute to better results in developed countries like America.

The name of the medication was the most misunderstood dosage instruction (77.6\%) which is lower than a study done in Harar, ${ }^{19}$ in Eastern Ethiopia only $37.2 \%$ of outpatients were able to recall the name of the product and in Botswana $(31 \%)^{20}$ recalled the name followed by the precaution of the medications $(77.3 \%)$.

The extent of the misunderstanding of the dose was $8.75 \%$ which is lower than studies done in Wollega $(17 \%),{ }^{16}$ Southwest Ethiopia and Turkey $(52.3 \%)^{21}$ and higher than a study done Dilla University Referral Hospital, Ethiopia $^{22}$ (2.1\%). Patients with low literacy were less able to state the exact number of pills delivered daily compared to those with adequate literacy. A similar study conducted in America showed that patients with low literacy were less able to understand instructions. ${ }^{17}$ This may be due to being unable to read or to misinterpretation of the instruction.

This study also demonstrated that the misunderstanding of the frequency of dose administration in DRH outpatients was $51.3 \%$ which is lower than a study done in Nekemte, Southwest Ethiopia (67.59\%). ${ }^{15}$ A comparable study done in America indicates that $79 \%$ of patients stated they took all TID doses within 12 hours. ${ }^{4}$ This shows as slightly higher than the finding of this study, this may be due to the study being done only on the TID frequency of drug administration, while the present study concerned PRN, BID, TID and QID. Another study on the effects of literacy on dosing instruction shows that $65.3 \%$ of patients with low literacy could not state the number of pills to be taken daily. ${ }^{17}$ Those findings explain the fact that low literacy has more influence on misunderstanding the frequency of dose administration.

About $58.59 \%$ of the respondents were not able to understand the duration of treatment, which is higher than a study done in Nekemte $(43 \%) .{ }^{15}$ The duration of drug administration may be considered an important aspect of drug therapy, especially patients take drugs for a long time but a number of the respondents had a poor understanding on the duration of treatment. This may be due to a lack of knowledge about the duration of drug treatment and/or they have forgotten the information given by the dispensers. 
Table 3 Distributions of Patients Misunderstanding of Dosing Instructions by General Characteristics of Patients Among Outpatients in Dessie Referral Hospital from February 10 to March 15, 2019

\begin{tabular}{|c|c|c|c|c|c|c|c|}
\hline \multicolumn{2}{|c|}{ General Characteristics } & \multicolumn{6}{|c|}{ Misunderstanding Dosing Instruction } \\
\hline & & \multicolumn{2}{|l|}{ Dose } & \multicolumn{2}{|l|}{ Frequency } & \multicolumn{2}{|l|}{ Duration } \\
\hline & & Frequency & $\%$ & Frequency & $\%$ & Frequency & $\%$ \\
\hline \multirow[t]{6}{*}{ Age (years) } & $15-24$ & 0 & 0 & 25 & 10.86 & 17 & 10.69 \\
\hline & $24-34$ & 13 & 0.48 & 93 & 40.43 & 51 & 32.07 \\
\hline & $35-44$ & 7 & 13.2 & 33 & 14.34 & 17 & 10.69 \\
\hline & $45-54$ & 5 & 12.82 & 30 & 13.04 & 10 & 6.28 \\
\hline & $55-64$ & 2 & 5.55 & 20 & 8.69 & 53 & 33.3 \\
\hline & +65 & 8 & 21.6 & 29 & 12.6 & 11 & 6.91 \\
\hline \multirow[t]{3}{*}{ Association } & & & & & & & \\
\hline & & $P=000$ & & $P=0.002$ & & $\mathrm{P}=0.000$ & \\
\hline & & $\chi^{2}=33.5$ & & $\chi^{2}=58.2$ & & $\chi^{2}=69.9$ & \\
\hline \multirow[t]{4}{*}{ Educational level } & Illiterate & 20 & 11.43 & $13 \mid$ & 74.86 & 72 & 41.14 \\
\hline & Primary school & 5 & 9.09 & 45 & 81.81 & 31 & 56.36 \\
\hline & Secondary school & 2 & 4.44 & 32 & 71.11 & 17 & 37.77 \\
\hline & Higher education & 8 & 7.07 & & 45.13 & 24 & \\
\hline \multirow[t]{3}{*}{ Association } & & & & & & & 21.23 \\
\hline & & $P=0.0001$ & & $P=0.0001$ & & $P=0.000$ & \\
\hline & & $\chi^{2}=|32.5|$ & & $\chi^{2}=68.94$ & & $\chi^{2}=91.83$ & \\
\hline \multirow[t]{2}{*}{ Sex } & Male & 20 & 9.85 & 133 & 65.52 & 67 & 33 \\
\hline & Female & 15 & 7.61 & 146 & 74.11 & 86 & \\
\hline \multirow[t]{3}{*}{ Association } & & & & & & & 43.65 \\
\hline & & $\mathrm{P}=0.08$ & & $P=0.27$ & & $\mathrm{P}=0.53$ & \\
\hline & & $\chi^{2}=2.92$ & & $\chi^{2}=1.21$ & & $\chi^{2}=0.408$ & \\
\hline \multirow[t]{2}{*}{ Residence } & Rural & 17 & 11.04 & 118 & 76.62 & 66 & 42.88 \\
\hline & Urban & 18 & 7.32 & 161 & 65.45 & 87 & \\
\hline \multirow[t]{3}{*}{ Association } & & & & & & & 35.37 \\
\hline & & $P=0.018$ & & $\mathrm{P}=0.0022$ & & $P=0.0364$ & \\
\hline & & $\chi^{2}=5.56$ & & $\chi^{2}=9.32$ & & $\chi^{2}=4.37$ & \\
\hline
\end{tabular}

Table 4 Distribution of Patients Misunderstanding of Dosing Instruction by Dosing Instruction Label Among Outpatients in Dessie Referral Hospital from February 10 to March 15, 2019

\begin{tabular}{|l|l|l|l|l|l|l|}
\hline \multirow{2}{*}{} & \multicolumn{2}{l}{ Patients Misunderstanding of Dosing Instruction } \\
\cline { 2 - 8 } & \multicolumn{2}{|l|}{ Dose } & Frequency & \multicolumn{2}{l|}{ Duration of Treatment } \\
\cline { 2 - 8 } & Frequency & $\%$ & Frequency & $\%$ & Frequency & $\%$ \\
\hline Labeled (written) & 13 & 11.4 & 83 & 72.81 & 51 & 44.74 \\
Unlabeled (verbal) & 22 & 7.7 & 196 & 68.53 & 102 & 35.66 \\
\hline
\end{tabular}

The majority of the outpatients received their medication from the pharmacy without labeling $(67.2 \%)$ which is similar to a study done in Wollega, Southwest Ethiopia $(68.3 \%)^{16}$ and better than a study done in Jimma Medical Center Southwest Ethiopia $(34.7 \%){ }^{3}$ Most of the medications were provided packed in blisters, strips, bottles and tubes and were dispensed for the patients without labeling instead drug information is given verbally.

The findings of this study also showed that the misunderstanding of dosing instruction is slightly higher in labeled 
(written) medication (11.4\%). This may be due to many terms commonly used on labels being confusing and not clear for many patients. As it was observed during the study period dosing instructions labeled on the container were not adequate that simply morning and evening terms were written on the medication label rather than the exact time intervals and duration of treatment. Another reason may be due to their inability to read the labeled instruction, since most respondents who misunderstood dosing instruction are illiterate and primary level. Also some patients without a label for their drug were chronic patients (hypertension, asthma) and patients with an over-counter drug dispensed and hence they were more aware of the dosing instruction.

In summary, patients of all ages would benefit from additional efforts to improve the clarity and comprehensibility of labeling on prescription drugs. There must be standard ways of labeling and the pharmacy professional must be trained periodically on medication labeling. The strength of the study was that most of the participants volunteered to participate actively during the interview. Our study has limitations, such as we were not able to study the relationship with health literacy, type of the medication, and underlying disease and we were able to investigate patient understanding only of the primary label on prescription medications. The association between misunderstanding of label instructions and medication error was not examined. This may be an area of interest for researchers to dig out more reasons why patients are not able to understand dosing instructions.

\section{Conclusion}

The prevalence of misunderstanding of dosing regimen instructions was high in outpatients of DRH. The amount (dosage) administration was the most understood instruction whereas the names of the medications were the most misunderstood patient medication instructions. Hence standard procedures must be developed to provide easy and clear dosing instructions to patients, and continuous training must be provided for pharmacists on proper communication of dosing instructions to patients.

\section{Data Sharing Statement}

The datasets used and/or analyzed during the current study are available from the corresponding author on reasonable request.

\section{Ethics Approval and Informed Consent}

Ethical clearance was issued from the College of Medicine and Health Science Ethical Committee, Wollo University (CMHS/
226/027/19). A letter of cooperation was written to Dessie Referral Hospital. Permission was obtained from the management of the hospital. The participants were informed about the purpose of the study and verbal consent was obtained from each participant and parental consent was also obtained for those participants under 18 years. The College of Medicine and Health Science Ethical Committee, Wollo University also approved the informed verbal consent process and to ensure patient confidentiality, participants were not identified by names or other personal identifiers. The study was conducted under the Declaration of Helsinki.

\section{Acknowledgment}

The authors would like to thank the Dessie Referral Hospital and the participants for their cooperation.

\section{Author Contributions}

All authors made substantial contributions to conception and design, acquisition of data, or analysis and interpretation of data; took part in drafting the article or revising it critically for important intellectual content; agreed to submit to the current journal; gave final approval of the version to be published; and agree to be accountable for all aspects of the work.

\section{Funding}

No financial support was obtained to conduct this study.

\section{Disclosure}

The authors report no conflicts of interest for this work.

\section{References}

1. Cláudia CR, Evelin SD, Graziela MA, Dayani G. Pharmacotherapy review: a proposal to improve medication adherence among hypertensive patients. BJPS. 2015;51(4):763-773.

2. Wolf MS, Davis TC, Shrank W, et al. Patient misinterpretations of prescription drug label instructions. Patient Educ Couns. 2007;67:293-300. doi:10.1016/j.pec.2007.03.024

3. Tadesse G, Dinku M. Patient knowledge of correct dosage regimen; the need for good dispensing practice. J Prim Care Community Health. 2019;10:1-7.

4. Richard NK, Steven DW, Jonathan C, Darren MA. Prevalence and nature of medication administration errors in health care settings: a systematic review of direct observational evidence. Ann Pharmacother. 2013;47:237-256. doi:10.1345/aph.1R147

5. Maria K, Desislava I, Anna G, Agnieszka S. The potential role of the pharmacist in supporting patients with depression - a literature-based point of view. Int Pharm Res Pract. 2020;9:49-63.

6. Alison GV, Ilene BV. Drug labeling and its impact on patient safety. Proceedings of the Human Factors and Ergonomics Society 52nd Annual Meeting; 2008:841-844.

7. Nicholas AH, Monica BP, Jesse AB, Brian LS. Patient misunderstanding of dosing instructions. J Gen Intern Med. 1996;11(6):325-327. doi:10.1007/BF02600041 
8. Freya $\mathrm{H}$. The outpatient prescription label as source of medication error. Am J Hosp Pharm. 1973;30(1):155-159.

9. Justine NC, Braund R. Preventing drug-related adverse events following hospital discharge: the role of the pharmacist. Integr Pharm Res Pract. 2017;6:61. doi:10.2147/IPRP.S104639

10. Beardsley R. Review of Literature Oral Patient Counseling by Pharmacists Proceeding of the National Symposium on Oral Counseling by Pharmacists About Prescription Medicines; 1997: 19-21.

11. World Health Organization. Promoting Rational Use of Medicines: Core Components; 2002.

12. Workye M, Admasu S, Abura T, et al. Clients' expectations from and satisfaction with medicine retail outlets in Gondar town, northwestern Ethiopia: a cross-sectional study. Integr Pharm Res Pract. 2015;4:1-12.

13. Ngoh LN. Health literacy: a barrier to pharmacist-patient communication and medication adherence. Pharm Today. 2009;15(8):45-57.

14. Vivia, Vreeland clark, R.N., ED. Outpatient services. Can J Hosp Pharm. 1971;24(1):196-198.

15. Diriba G, Alemkere G, Gedamu M. Assessment of patients misunderstanding regarding dosage regimen instructions at Nekemte Referral Hospital, Ethiopia. J Fam Med. 2018;5(5):1153.

16. Ababo T, Tesfahun C. Assessment of patients misunderstanding of dosage regimen instructions among adolescent and adult outpatients in ethiopia: the case of a primary hospital. Int J Pharm Sci Res. 2014;5(8):445-453.
17. Terry CD, Alex DF, Pat FB, et al. Improving patient understanding of prescription drug label instructions. J Gen Intern Med. 2008;24 (1):57-62.

18. Welma WA, Luiz CP, Romana SG, Renato MS, Marcio GO. Factors associated with older patients' misunderstandings of medication dosage regimen instructions after consultation in primary care in Brazil. J Eval Clin Pract. 2020;1-9.

19. Nigatu H, Dumessa E, Mekonnen S. Exit-knowledge of ambulatory patients about medications dispensed in government hospital in Eastern Ethiopia: the need for focused patient counseling. Front Public Health. 2018;6(254):1-8.

20. Boonstra E, Lindbaek M, Ngome E, Tshukudu K, Fugelli P. Labelling and patient knowledge of dispensed drugs as quality indicators in primary care in Botswana. Qual Saf Health Care. 2003;12:168-175. doi:10.1136/qhc. 12.3 .168

21. Hulya B, Gulay T, Ümran D, Sevgisun K. How much do ED patients know about medication prescribed for them on discharge? A pilot study in Turkey. J Emerg Nurs. 2013;39(2):27-32. doi:10.1016/j. jen.2008.12.017

22. Aychew M, Dereje K, Ramanji RT, Fanta G. misunderstandings of dosage instructions in Dilla referral hospital in Ethiopia. Med Data. 2015;7(1):027-031.
Risk Management and Healthcare Policy

\section{Publish your work in this journal}

Risk Management and Healthcare Policy is an international, peerreviewed, open access journal focusing on all aspects of public health, policy, and preventative measures to promote good health and improve morbidity and mortality in the population. The journal welcomes submitted papers covering original research, basic science, clinical \& epidemiological studies, reviews and evaluations,

\section{Dovepress}

guidelines, expert opinion and commentary, case reports and extended reports. The manuscript management system is completely online and includes a very quick and fair peer-review system, which is all easy to use. Visit http://www.dovepress.com/testimonials.php to read real quotes from published authors. 